\title{
ANALISIS TINGKAT KEPUASAN PELANGGAN TERHADAP PENJUALAN AIR MINUM ISI ULANG DENGAN MENGGUNAKAN METODE ROUGH SET
}

(Studi Kasus: Rihata Water)

\author{
Tania Dian Tri Utami ${ }^{1}$, Dedy Hartama ${ }^{2}$, Agus Perdana Windarto ${ }^{3}$, Solikhun ${ }^{4}$ \\ ${ }^{1}$ Mahasiswa S-1 Sistem Informasi, STIKOM Tunas Bangsa, Jalan Sudirman Blok A No. 1, 2, 3 Kota \\ Pematangsiantar \\ ${ }^{2,3,4}$ Dosen S-1 Sistem Informasi, STIKOM Tunas Bangsa, Jalan Sudirman Blok A No. 1, 2, 3 Kota \\ Pematangsiantar \\ E-mail : taniadiantriutami.tdtu5@gmail.com, dedyhartama@amiktunasbangsa.ac.id, \\ zhantura.gusti@gmail.com,solikhun@amiktunasbangsa.ac.id
}

\begin{abstract}
Abstrak
Kepuasan Pelanggan dalam penjualan air minum isi ulang merupakan hal penting. Mengingat penjulan air minum isi ulang yang semakin meningkat pada tiap daerah. Pada zaman sekarang, masyarakat lebih memilih konsumsi air minum isi ulang dikarenakan lebih hemat waktu dan biaya. Meningkatnya penjualan air minum isi ulang juga merupakan akibat dari susahnya mendapatkan air bersih untuk konsumsi. Penjualan air minum yang baik juga berdasarkan pada tingkat kebersihan air, mutu pelayanan, harga, serta waktu pengisian air tersebut. Dalam hal ini, penulis melakukan analisis pada Depot Air Minum Isi Ulang Rihata Water di Jl. Nirwana Huta VII, Desa Purbasari, Kec. Tapian Dolok, Kab. Simalungun. Analisis yang digunakan adalah dengan menggunakan metode Rough Set. Metode ini diharapkan dapat mengetahui kepuasan pelanggan terhadap penjualan air minum isi ulang. Analisis ini diharapkan dapat membantu menemukan tingkat kepuasan pelanggan terhadap penjualan air minum isi ulang. Dan dari hasilnya, analisis ini dapat menunjukkan pemberian hadiah terhadap pelanggan sesuai dengan kriteria tingkat kepuasannya.
\end{abstract}

Kata kunci: Kepuasan pelanggan; air minum isi ulang; data mining; rough set, rosetta

\section{Pendahuluan}

Air minum adalah kebutuhan vital bagi manusia. Seiring dengan sulitnya pasokan air bersih, air minum isi ulang menjadi pilihan utama bagi masyarakat. Dikarenakan pula tingginya aktifitas dan kebutuhan, menjadikan air minum isi ulang yang praktis sebagai pilihan efisien. Dan saat ini, mulai berkembang pesat usaha air minum isi ulang. Contohnya usaha Depot air minum isi ulang "Rihata Water" yang bertempat di Jl. Nirwana, Desa Purbasari, Kecamatan Tapian Dolok, Kabupaten Simalungun, Sumatera Utara. Dalam dunia usaha, pasti mengalami persaingan antara pelaku usaha. Maka kepuasan pelanggan menjadi penilaian penting. Karena pelanggan merupakan pasar besar dalam meningkatkan penjualan. Semakin hari, jumlah pelanggan juga semakin besar. Maka, dalam menganalisa hal ini solusi yang digunakan adalah data mining. Data mining merupakan pencarian informasi menarik dalam sebuah data terpilih di database.

Pengimplementasian data mining, banyak algoritma yang dapat digunakan. Salah satunya adalah Rough Set. Algoritma Rough Set ini dapat digunakan dalam menganalisis tingkat kepuasan pelanggan terhadap penjualan air minum 
isi ulang. Dengan menggunkan metode Rough Set, aspek penilaiannya adalah: waktu pengisian air minum isi ulang, pengantaran air minum ke rumah-rumah pelanggan, kebersihan air minum, dan harga yang diberikan oleh pihak pengusaha. Keluaran yang dihasilkan adalah kepuasan pelanggan. Tujuan dari penerapan metode Rough Set ini adalah membantu pemilik usaha dalam mengetahui tingkat kepuasan pelanggan berdasarkan data-data yang ada. Manfaat yang diperoleh adalah dapat menentukan pelanggan yang berhak mendapatkan hadiah sesuai dengan tingkat kepuasan yang diberikan melalui metode Rough Set.

\section{Kajian Teori}

Data mining adalah proses untuk menemukan pengetahuan, pola, dan informasi yang menarik dari sekumpulan data berukuran besar melalui proses deskriptif, pemahaman dan prediksi dengan menggunakan suatu model atau algoritma (Zaki dan Meira, 2014). Data mining adalah proses yang menggunakan teknik statistik, matematika, kecerdasan buatan, dan machine learning untuk mengekstraksi dan mengidentifikasi informasi yang bermanfaat dan pengetahuan yang terkait dari berbagai database besar[1].

Istilah data mining dan Knowledge Discovery in Database (KDD) sering kali digunakan secara bergantian untuk menjelaskan proses penggalian informasi tersembunyi dalam suatu basis data yang besar. Sebenarnya kedua istilah tersebut memiliki konsep yang berbeda, tetapi berkaitan satu sama lain. Dan salah satu tahapan dalam keseluruhan proses KDD adalah data mining. Proses KDD secara garis besar dapat dijelaskan sebagai berikut (Fayyad, 1996) [2].

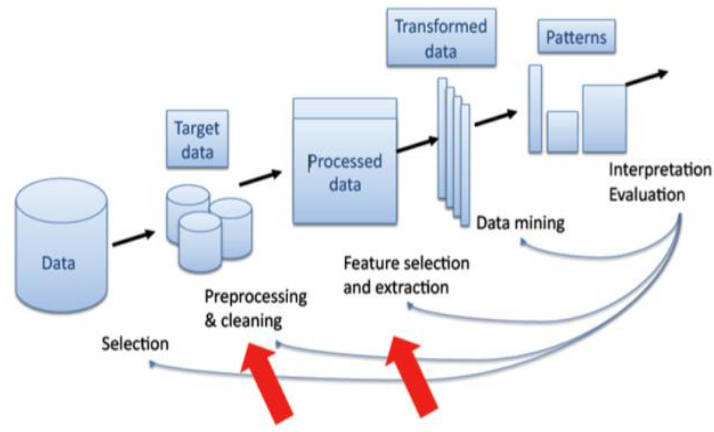

Gambar 1. Proses KDD

\section{Metode Penelitian}

Metode Rough Set merupakan teknik yang efisien untuk knowledge discovery in database (KDD) proses dan data mining. Tujuan dari analisis Rough Set adalah untuk mendapatkan perkiraan ruleyang singkat dari suatu tabel. Hasil dari analis rough set dapat digunakan dalam proses data mining dan knowledge discovery. Teknik ini digunakan untuk menangani masalah uncertainly, missing data, uncompleted, inconsistency data, imprecision dan vagueness (tidak pasti, data hilang, tidak lengkap, tidak selaras, ketidaktepatan, ketidakjelasan)[3]. Berikut tahapantahapan di dalam penggunaan algoritma Rough Set:

1. Data Selection: Pemilihan data yang akan digunakan

2. Decision System: Pembentukan atribut kondisi dan atribut keputusan.

3. Equivalence Class: Pembentukan dengan menghilangkan data yang berulang.

4. Discernibility Matrix Modulo D: Pembentukan matriks yang berisikan perbandingan antar data yang berbeda atribut kondisi dan atribut keputusan.

5. Menghasilkan reduct dengan menggunakan aljabar boolean.

6. Menghasilkan rule (pengetahuan).

Dalam rough set, sebuah set data direpresentasikan sebagai sebuah tabel, dimana baris dalam tabel 
merepresentasikan objek dan kolomkolom merepresentasikan atribut dari objek-objek tersebut. Tabel tersebut disebut dengan information system yang dapat digambarkan sebagai:

Di mana $U$ adalah set terhingga yang tidak kosong dari objek yang disebut dengan universe dan A set terhingga tidak kosong dari atribut dimana:

$$
\mathrm{IS}=\{\mathrm{U}, \mathrm{A}\}
$$

Untuk tiap $\alpha$ E A. Set $V \alpha$ disebut value set dari a.

$\mathrm{U}=\left\{\mathrm{e}_{1}, \mathrm{e}_{2}, \ldots, \mathrm{e}_{\mathrm{m}}\right\}$ merupakan sekumpulan example dan

$\mathrm{A}=\left\{\mathrm{a}_{1}, \mathrm{a}_{2}, \ldots, \mathrm{a}_{\mathrm{n}}\right\}$ yang merupakan attribute kondisi

secara berurutan[4]

\section{Hasil dan Pembahasan}

Berikut merupakan data pelanggan awal yang belum diolah:

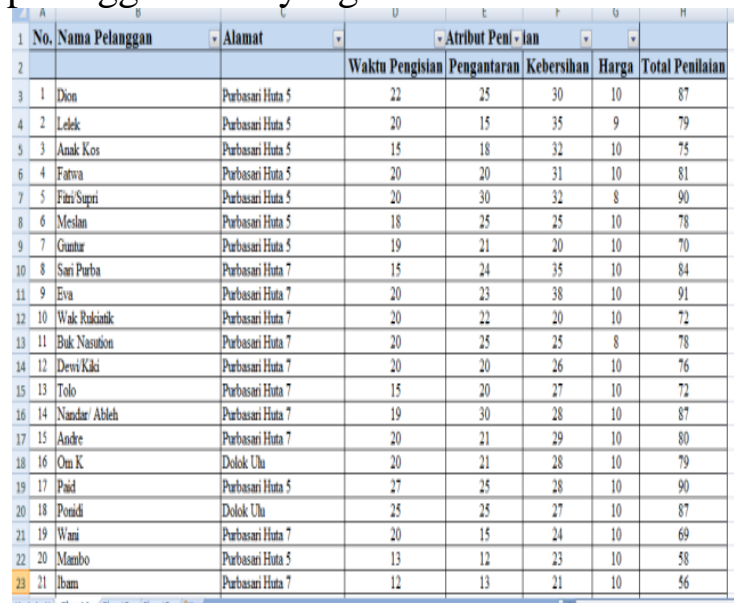

Gambar 2. Data pelanggan

\section{Data Selection}

Data yang digunakan merupakan data penjualan pada Depot Air Minum Isi Ulang "Rihata Water" di Jl. Nirwana, Desa Purbasari Huta VII, Kecamatan Tapian Dolok, Kabupaten Simalungun beserta dengan atribut: waktu pengisian air, pengantaran, kebersihan, dan harga.

Dalam rangka menganalisis kepuasan pelanggan terhadap penjualan air minum isi ulang didasarkan pada sejumlah kompenen berikut ini:

1. Waktu pengisian air (Maks. 20\%)
2. Delivery atau Pengantaran (Maks. $30 \%$ )

3. Kebersihan (Maks. 40\%)

4. Harga (Maks. 10\%)

Komponen penilaian yang ada pada waktu pengisian air dapat dilihat pada Tabel 1.

Tabel 1. Komponen penilaian waktu pengisian air

\begin{tabular}{lc}
\hline Kriteria yang dinilai & Bobot \\
\hline Pencucian Botol & $7.5 \%$ \\
Sterilisasi Botol & $7.5 \%$ \\
Pengisian Air & $5 \%$ \\
\hline
\end{tabular}

Komponen penilaian pada delivery dapat dilihat pada Tabel 2.

Tabel 2. Komponen penilaian delivery

\begin{tabular}{lc}
\hline \multicolumn{1}{c}{ Kriteria yang dinilai } & Bobot \\
\hline Pengambilan Botol Kosong & $10 \%$ \\
Pengantaran Botol Berisi Air & $20 \%$ \\
Minum Isi Ulang & \\
\hline
\end{tabular}

Komponen penilaian yang ada pada Kebersihan dapat dilihat pada Tabel 3.

Tabel 3. Komponen penilaian aspek kebersihan

\begin{tabular}{lcc}
\hline \multicolumn{2}{c}{ Kriteria yang dinilai } & Bobot \\
\hline Pembersihan botol secara & $15 \%$ \\
detail & $15 \%$ \\
Menjaga kualitas air & $10 \%$ \\
Membersihkan peralatan & \\
\hline
\end{tabular}

Komponen penilaian yang ada pada Hargadapat dilihat pada Tabel 4.

Tabel 4. Komponen penilaian harga

\begin{tabular}{lc}
\hline \multicolumn{1}{c}{ Kriteria yang dinilai } & Bobot \\
\hline $\begin{array}{l}\text { Memberi harga jual yang } \\
\text { terjangkau }\end{array}$ & $5 \%$ \\
Sesuai kualitas produk & $5 \%$ \\
\hline
\end{tabular}

\section{Data Transformation}

Total hasil penilaian kemudian dijadikan dalam bentuk kategori dengan ketentuan:

$<50$ dikategorikan Kurang $=1$

$51 \leq \mathrm{X} \leq 70$ dikategorikan Cukup $=2$

$71 \leq \mathrm{X} \leq 80$ dikategorikan Baik $=3$

$81 \leq \mathrm{X} \leq 100$ dikategorikan Sangat Baik $=4$ 


\section{Decision System}

Hasil decision system datanya dapat dilihat pada Gambar 1, dengan contoh data yang digunakan adalah sebanyak 5 (lima) data:

\begin{tabular}{|c|c|c|c|c|c|c|c|}
\hline \multirow{2}{*}{$\mathrm{No}$} & \multirow{2}{*}{ Tama Pelanggan } & 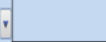 & FAtribut Penil - & ial & 7 & & \multirow{2}{*}{ Keputusan } \\
\hline & & \multicolumn{3}{|c|}{ Taktu Pengisian Pengantaran Kebersihan } & Harga & Total Penilgian & \\
\hline 1 & & 12 & 25 & 30 & 10 & 87 & Smagat Pus \\
\hline 2. & & 20 & 15 & 35 & 9 & 9 & Pexs \\
\hline & atakos & 15 & 18 & 3. & 10 & 75 & Pexs \\
\hline 4 & 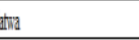 & 20 & DI & 31 & 10 & 81 & Sangat Pues \\
\hline & thisumin & 20. & 30 & 32 & 8 & 90 & Sangat Pus \\
\hline & Eedan & 18 & 25 & 15 & 10 & 78 & Pex \\
\hline & min & 19 & 21 & 20 & 10 & 70 & Pews \\
\hline & rifiputa & 15 & 24 & 35 & 10 & 84 & Sangat Puex \\
\hline 98 & & 20 & 3 & 38 & 10 & 91 & Suggat Pues \\
\hline & WRuldok & 20 & 12 & 20 & 10 & 7 & Pexs \\
\hline
\end{tabular}

Gambar 3. Pembentukan pada decison system Pertama

\section{Pembentukan Equivalence Class}

Sebelum melakukan pembentukan

Equivalence Class, maka lakukan transformasi kembali kepada atribut A (Waktu Pengisian Air), atribut B (Delivery), atribut C (Kebersihan), dan atribut D (Harga).

3 kelompok, yaitu:

$0 \leq \mathrm{X} \leq 8=1$

$9 \leq \mathrm{X} \leq 16=2$

$17 \leq \mathrm{X} \leq 24=3$

$25 \leq \mathrm{X} \leq 32=4$

Untuk atribut B dikelompokkan menjadi

3 kelompok, yaitu :

$0 \leq \mathrm{X} \leq 9=1$

$10 \leq \mathrm{X} \leq 18=2$

$19 \leq X \leq 27=3$

$28 \leq \mathrm{X} \leq 36=4$

Untuk atribut $\mathrm{C}$ dikelompokkan menjadi 4 kelompok, yaitu :

$0 \leq \mathrm{X} \leq 12=1$

$13 \leq \mathrm{X} \leq 24=2$

$25 \leq \mathrm{X} \leq 36=3$

$37 \leq \mathrm{X} \leq 50=4$

Untuk atribut $\mathrm{D}$ dikelompokkan menjadi

2 kelompok, yaitu :

$0 \leq \mathrm{X} \leq 2=1$

$3 \leq \mathrm{X} \leq 5=2$

$6 \leq \mathrm{X} \leq 8=3$

$9 \leq \mathrm{X} \leq 15=4$
Sehingga hasil pembentukan decision system dapat dilihat pada Gambar 4.

\begin{tabular}{|c|c|c|c|c|c|c|}
\hline \multirow[t]{2}{*}{ No. Nama Pelanggan } & \multicolumn{4}{|c|}{ Atribut Penilaian } & \multirow[b]{2}{*}{ Jumlah Nilai } & \multirow{2}{*}{ Keputusan } \\
\hline & Maktu Pengisian & Pengantaran & Kebersihan & Harga & & \\
\hline 1 Dion & 4 & 3 & 3 & 4 & 4 & 4 \\
\hline 2 Letek & 3 & 2 & 3 & 4 & 3 & 3 \\
\hline \begin{tabular}{|l|l|} 
& Anakk Kos \\
\end{tabular} & 3 & 2 & 3 & 4 & 3 & 3 \\
\hline \begin{tabular}{|l|l|}
4 & Fatria \\
\end{tabular} & 3 & 3 & 3 & 4 & 4 & 4 \\
\hline 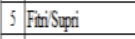 & 3 & 4 & 3 & 3 & 4 & 4 \\
\hline \begin{tabular}{|l|l|}
6 & Meslan \\
\end{tabular} & 3 & 3 & 3 & 4 & 3 & 3 \\
\hline 7 Guntr & 3 & 3 & 2 & 4 & 3 & 3 \\
\hline 8 Sari Purba & 3 & 3 & 3 & 4 & 4 & 4 \\
\hline 9 Era & 3 & 3 & 4 & 4 & 4 & 4 \\
\hline 10 Wak Rubiatik & 3 & 3 & 2 & 4 & 3 & 3 \\
\hline
\end{tabular}

Gambar 4. Decision system setelah transformasi ke-2

Pembentukan Equivalence Class dilakukan dengan cara menghilangkan data yang memiliki kesamaan, maka pada Equivalence Class data tersebut menjadi 1 (Satu) Record. Adapun hasil dari pembentukan Equivalence Class dapat dilihat pada Tabel 5.

Tabel 5. Equivalence class

\begin{tabular}{|c|c|c|c|c|c|}
\hline & $\overline{\mathrm{A}}$ & $\bar{B}$ & $\bar{C}$ & $\bar{D}$ & $\overline{\mathrm{K}}$ \\
\hline $\mathrm{EC} 1$ & $\overline{4}$ & 3 & 3 & $\overline{4}$ & 4 \\
\hline EC2 & 3 & 2 & 3 & 4 & 3 \\
\hline EC3 & 3 & 2 & 3 & 4 & 3 \\
\hline EC4 & 3 & 3 & 3 & 4 & 4 \\
\hline EC5 & 3 & 4 & 3 & 3 & 4 \\
\hline EC6 & 3 & 3 & 3 & 4 & 3 \\
\hline EC7 & 3 & 3 & 2 & 4 & 3 \\
\hline EC8 & 3 & 3 & 3 & 4 & 4 \\
\hline EC9 & 3 & 3 & 4 & 4 & 4 \\
\hline EC10 & 3 & 3 & 2 & 4 & 3 \\
\hline
\end{tabular}

Keterangan:

Atribut A (Waktu Pengisian Air), Atribut B (Delivery), Atribut C (Kebersihan), dan Atribut D (Harga).

\section{Pembentukan Discernibility Matrix Modulo D}

Discernibility Matrix Modulo D merupakan matriks yang berisikan perbandingan antar data yang berbeda atribut kondisi dan atribut keputusan. Data dengan atribut kondisi yang berbeda, tetapi atribut keputusan yang sama tetap dianggap sama. Adapun Discernibility Matrix Modulo D dapat dilihat pada Gambar 3. 


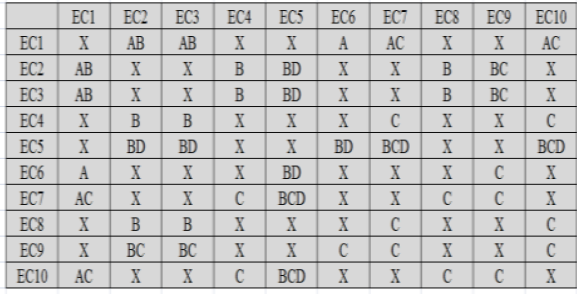

Gambar 5. Discernibility Matrix

\section{Menghasilkan Reduct dengan Menggunakan Aljabar Boolean}

Adapun reduct yang dihasilkan dapat dilihat pada Tabel 6 .

Tabel 6. Reduct

\begin{tabular}{|c|c|c|c|}
\hline Class & CNF of Boolean Function & Prime Implicant & Reducts \\
\hline $\mathrm{EC} 1$ & $\begin{array}{c}(\mathrm{AvB})^{\wedge} \\
(\mathrm{AvB})^{\wedge}(\mathrm{A})^{\wedge}(\mathrm{AvC})^{\wedge}(\mathrm{AvC})\end{array}$ & AvBvA & $\{\mathrm{A}\},\{\mathrm{B}\}$ \\
\hline $\mathrm{EC} 2$ & $(\mathrm{AvB})^{\wedge}(\mathrm{B})^{\wedge}(\mathrm{BvD})^{\wedge}(\mathrm{B})^{\wedge}(\mathrm{BvC})$ & $A B v A D v B$ & $\begin{array}{c}\{\mathrm{A}, \mathrm{B}\} \\
\{\mathrm{A}, \mathrm{D}\},\{\mathrm{B}\}\end{array}$ \\
\hline EC3 & $(\mathrm{AvB})^{\wedge}(\mathrm{B})^{\wedge}(\mathrm{BvD})^{\wedge}(\mathrm{B})^{\wedge}(\mathrm{BvC})$ & $A B v A D v B$ & $\begin{array}{c}\{\mathrm{A}, \mathrm{B}\} \\
\{\mathrm{A}, \mathrm{D}\},\{\mathrm{B}\}\end{array}$ \\
\hline $\mathrm{EC} 4$ & $(\mathrm{~B})^{\wedge}(\mathrm{B})^{\wedge}(\mathrm{C})^{\wedge}(\mathrm{C})$ & $\mathrm{BvC}$ & $\begin{array}{l}\{\mathrm{B}\} \\
\{\mathrm{C}\}\end{array}$ \\
\hline EC5 & $\begin{array}{c}(\mathrm{BvD})^{\wedge}(\mathrm{BvD})^{\wedge}(\mathrm{BvD})^{\wedge}(\mathrm{BvCvD})^{\wedge} \\
(\mathrm{BvCvD})\end{array}$ & $\mathrm{BvCDvBDvBCvD}$ & $\begin{array}{c}\{\mathrm{B}\}, \\
\{\mathrm{C}, \mathrm{D}\} \\
\{\mathrm{B}, \mathrm{D}\} \\
\{\mathrm{B}, \mathrm{C}\} \\
\{\mathrm{D}\}\end{array}$ \\
\hline EC6 & $(\mathrm{A})^{\wedge}(\mathrm{BvD})^{\wedge}(\mathrm{C})$ & $\mathrm{ABvACvDC}$ & $\begin{array}{c}\{\mathrm{A}, \mathrm{B}\},\{\mathrm{A}, \mathrm{C}\} \\
\{\mathrm{D}, \mathrm{C}\}\end{array}$ \\
\hline EC7 & $\begin{array}{c}(\mathrm{AvC})^{\wedge}(\mathrm{C})^{\wedge}(\mathrm{BvCvD})^{\wedge}(\mathrm{C})^{\wedge}(\mathrm{C})^{\wedge}( \\
\mathrm{C})\end{array}$ & $\mathrm{AvBvC}$ & $\begin{array}{l}\{\mathrm{A}\}, \\
\{\mathrm{B}\}, \\
\{\mathrm{C}\}\end{array}$ \\
\hline $\mathrm{EC} 8$ & $(\mathrm{~B})^{\wedge}(\mathrm{B})^{\wedge}(\mathrm{C})^{\wedge}(\mathrm{C})$ & $\mathrm{BvC}$ & $\begin{array}{l}\{B\}, \\
\{C\}\end{array}$ \\
\hline EC9 & $\begin{array}{c}(\mathrm{AvC})^{\wedge}(\mathrm{C})^{\wedge}(\mathrm{BvCvD})^{\wedge}(\mathrm{C})^{\wedge}(\mathrm{C})^{\wedge}( \\
\mathrm{C})\end{array}$ & $\mathrm{AvBvC}$ & $\begin{array}{l}\{\mathrm{A}\}, \\
\{\mathrm{B}\} \\
\{\mathrm{C}\}\end{array}$ \\
\hline EC10 & $(\mathrm{BvC})^{\wedge}(\mathrm{BvC})^{\wedge}(\mathrm{C})^{\wedge}(\mathrm{C})^{\wedge}(\mathrm{C})$ & $\mathrm{C}$ & $\{C\}$ \\
\hline
\end{tabular}

General Rule

Adapun rule yang dihasilkan berdasarkan Reduct adalah sebagai berikut:

A. $\{\mathrm{A}\}$

1. IF Waktu Pengisian (22) THEN Keputusan (Sangat Puas)

2. IF Waktu Pengisian (20) THEN Keputusan (Puas) OR Keputusan (Sangat Puas)

3. IF Waktu Pengisian (15) THEN Keputusan (Puas) OR Keputusan (Sangat Puas)

4. IF Waktu Pengisian(18) THEN Keputusan (Puas)

5. IF Waktu Pengisian(19) THEN Keputusan (Puas)
B. $\{\mathrm{B}\}$

1. IF Pengantaran (25) THEN Keputusan (Sangat Puas) OR Keputusan (Puas)

2. IF Pengantaran (15) THEN Keputusan (Puas)

3. IF Pengantaran (18) THEN Keputusan (Puas)

4. IF Pengantaran (20) THEN Keputusan (Sangat Puas)

5. IF Pengantaran (30) THEN Keputusan (Sangat Puas)

6. IF Pengantaran (21) THEN Keputusan (Puas)

7. IF Pengantaran (24) THEN Keputusan (Sangat Puas) 
8. IF Pengantaran (23) THEN

Keputusan (Sangat Puas)

9. IF Pengantaran (22) THEN

Keputusan (Puas)

Penerapan data mining dengan konsep algoritma rough set akan semakin berkembang. Algoritma rough set yang memiliki atribut kondisi Waktu Pengisian Air, Delivery, Kebersihan, dan Harga dapat digunakan untuk menganilisa kepuasan pelanggan terhadap penjualan air minum isi ulang sehingga dapat membantu Rihata Water dalam meningkatkan tingkat penjualan air minum isi ulang.

Berikut ini merupakan Hasil atau Rule yang didapat dengan menggunakan tools Rosetta 1.4.41:

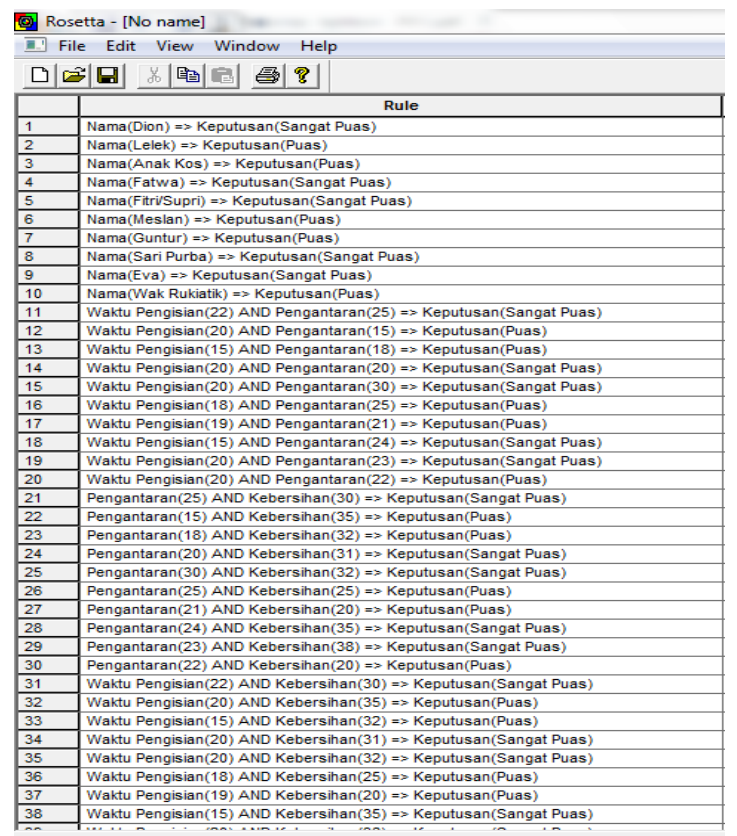

Gambar 6. Rule pada Rosetta 1.4.41

\section{Kesimpulan}

Algoritma Rough Set merupakan metode data mining sederhana yamg dapat digunakan oleh sistem analisis kepuasan pelanggan terhadap penjualan air minum isi ulang. Atribut yang digunakan: Waktu Pengisian Air, Delivery, Kebersihan, dan Harga dapat digunakan dalam sistem analisis kepuasan pelanggan terhadap penjualan air minum isi ulang. Penggunaan aplikasi rosetta dapat membantu dalam pengambilan keputusan dalam mengetahui tingkat kepuasan pelanggan serta dapat menghasilkan keputusan pemberian hadiah pada pelanggan berdasarkan tingkat kepuasannya.

\section{Daftar Pustaka}

[1]. Hartama, Dedy dan Hartono. 2016. Analisis Kinerja Dosen STMIK IBBI dengan Menggunakan Metode Rough Set. Jurnal Seminar Nasional Teknologi Informasi dan Multimedia 2016. ISSN: 23023805

[2].http://recommendersystems.readth edocs.org/en/latest/datamining. html diakses tanggal 28 Januari 2016

[3]. Kurniawati, Siti. 2015. Penerapan Metode Rough Set Pada Tingkat Kepuasan Konsumen Terhadap Kualitas Pelayanan Hotel (Studi Kasus Hotel Graha Buana Medan). Majalah Jurnal Informasi dan Teknologi Ilmiah (INTI), Volume: V, Nomor: 2, Januari 2015, ISSN: $2339-210 X$, hal 138142.

[4]. Nurhayati. 2014. Metode Rough Set untuk Melihat Perilaku Suami yang Menjadi Akseptor KB Vasektomi. Majalah Jurnal Informasi dan Teknologi Ilmiah (INTI), Volume: III, Nomor: 2, Juni 2014, ISSN: 2339-210X, hal 94-99. 